\title{
Pentoxifylline influences the autocrine function of organ cultured donor corneas and enhances endothelial cell survival
}

\author{
A C Sobottka Ventura, M Böhnke
}

\begin{abstract}
Backgroundlaims-Scientific interest in pentoxifylline has been reawakened owing to the recognised effects of this drug on immune functions, particularly its influence on cytokine production. In a previous study, the authors demonstrated that spiking of organ culture media with endotoxin elicited a marked enhancement in the release of IL-6 and IL-8 from corneal tissue and that these events coincided with degenerative changes in endothelial cells and a higher incidence of actual loss among this population. Since traces of donor derived endotoxin can be detected in up to $50 \%$ of corneal organ cultures, this substance may have a direct influence on graft viability or trigger inflammatory responses in the host. They, therefore, wished to ascertain whether supplementation of media with pentoxifylline improved endothelial cell survival in organ cultured donor corneas.
\end{abstract}

Methods-12 fellow pairs of donor corneas were cultured for 20 days, with a change of medium on day 10: One of each pair was incubated in the absence, and the other in the presence, of pentoxifylline $(25 \mu \mathrm{g} / \mathrm{ml})$. Samples of medium were withdrawn at regular intervals during the course of incubation and screened for cytokines IL-6, IL-8, and prostaglandin E2 by ELISA. Endothelial cell morphology and numerical density were assessed on days 0,10 and 20.

Results-Addition of pentoxifylline to organ culture media led to a significant improvement in endothelial cell survival. This drug also elicited a significant increase in the level of IL- 6 and marginally suppressed that of IL-8 during the initial 10 day phase of incubation. During the second 10-20 day phase, the level of both IL-6 and IL-8 decreased significantly in the presence of pentoxifylline, the relation between these two cytokines being the inverse of that observed in the absence of the drug. No significant changes in the level of prostaglandin E2 were apparent. Conclusion-The addition of pentoxifylline to organ culture media leads, ultimately, to a suppression of IL-6 and IL-8 secretion by corneal tissue. The potentially damaging effects of these cytokines are thereby quelled, as evidenced by the improvement in endothelial cell survival. (Br f Ophthalmol 2001;85:1110-1114)
Pentoxifylline, a derivative of methylxanthine theobromine, acts as a phosphodiesterase inhibitor and thereby elevates the levels of cAMP. This drug, which is widely used in the treatment of peripheral vascular disorders, is claimed to improve microcirculation and tissue oxygenation by increasing the flexibility of erythrocytes and by reducing blood viscosity and platelet aggregation.

Interest in pentoxifylline has been recently reawakened because of its reported suppressive action on immune functions, ${ }^{1-3}$ particularly on cytokine production. ${ }^{3-6}$ It has been shown to be beneficial in the treatment of endotoxaemia, ${ }^{7-12}$ tumour induced cachexia, ${ }^{13}$ inflammatory bowel disease, ${ }^{14}{ }^{15}$ and AIDS, ${ }^{16}$ as well as in organ transplantation. ${ }^{17-21}$ Pentoxifylline probably acts primarily by inhibiting tumour necrosis factor, ${ }^{10}{ }^{12}{ }^{1321-24}$ but other cytokines, such as IL-1 $\beta,{ }^{1025}$ IL- $2,{ }^{26}$ IL- $6,{ }^{70}$ IL-8, ${ }^{27}{ }^{28}$ IL-10, ${ }^{16}{ }^{25}$ $\gamma$-interferon, ${ }^{29}$ and transforming growth factor $\beta,{ }^{30}$ vascular endothelial growth factor, as well as adhesion molecules, ${ }^{31}$ are also implicated. This agent additionally reduces leucocytosis and neutrophilia, and inhibits the phagocytic and microbicidal activities of monocytes, macrophages and neutrophils, ${ }^{12} 3233$ as well as degranulation in the latter. ${ }^{8}$ It also modulates fibrinolytic activity, both in vitro and in vivo, ${ }^{6}$ by suppressing tissue type plasminogen activator and its inhibitor. ${ }^{34}$

In a previous study, we demonstrated that spiking of organ culture media with endotoxin markedly enhanced the release of IL- 6 and IL-8 from corneal tissue. These events coincided with degenerative changes and a higher incidence of death in endothelial cells. ${ }^{35}$ Since traces of donor derived endotoxin can be detected in up to $50 \%$ of organ culture corneas, ${ }^{36}$ it may be directly implicated in graft viability or in the triggering of host inflammatory responses. The addition of pentoxifylline to such cultures could have a beneficial effect on the condition of the donor corneas or even on the clinical course after grafting.

We have already tested the potential toxic effects of pentoxifylline on cultured cells and defined its therapeutic range. ${ }^{37}$ In the present study, we wished to ascertain whether this drug improved endothelial cell survival when added to the medium bathing organ cultured donor corneas, and whether this putative effect was correlated with the release of various cytokines.

Materials and methods

EVALUATION OF DONOR CORNEAS AND ORGAN CULTURING CONDITIONS

Donor globes were removed within 50 hours of death and examined with a slit lamp. The eyes 


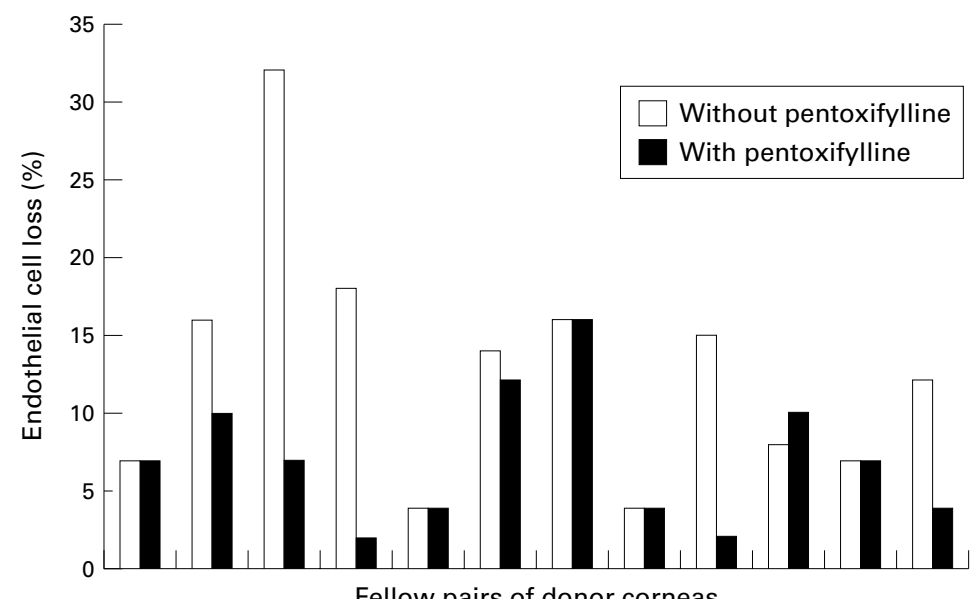

Fellow pairs of donor corneas

Figure 1 The percentage of endothelial cell loss incurred by 12 fellow pairs of donor corneas (I-XII) after 20 days of incubation. Cultures of left corneas (solid bars) were supplemented with $25 \mathrm{\mu g} / \mathrm{ml}$ of pentoxifylline; those of right ones (open bars) served as controls.

were disinfected with PVP-iodine, and corneoscleral buttons then excised microsurgically under laminar flow conditions. Tissue discs were immersed in MEM (Seromed), and the morphological status of the endothelium evaluated according to standard criteria by inverted phase contrast microscopy. ${ }^{38}$ Corneal buttons were then transferred to wells containing buffered saline (Alcon) to promote swelling of the intercellular spaces. The endothelium was photographed using a high resolution

Table 1 Endothelial cell numerical densities and losses incurred (4) by 17 (I-XVII) fellow pairs (right eye and left eye) of donor corneas after an initial 10 day phase and after medium change by 12 fellow pairs (I-XII) after another 10 day phase

\begin{tabular}{|c|c|c|c|c|}
\hline \multirow[b]{2}{*}{ Corneal pair no } & \multicolumn{3}{|c|}{ Cell density $/ \mathrm{mm}^{2}$} & \multirow[b]{2}{*}{ Total cell loss } \\
\hline & $\begin{array}{l}\text { Before organ } \\
\text { culture }\end{array}$ & $\begin{array}{l}\text { After } 10 \text { days of } \\
\text { organ culture }\end{array}$ & $\begin{array}{l}\text { After } 20 \text { days of } \\
\text { organ culture }\end{array}$ & \\
\hline I RE & 2500 & $2400(\Delta 100)$ & $2100(\Delta 300)$ & 400 \\
\hline I LE & 2500 & $2300(\Delta 200)$ & $2250(\Delta 50)$ & 250 \\
\hline II RE & 2150 & $2200(\Delta+50)$ & $1750(\Delta 450)$ & 400 \\
\hline II LE & 2150 & $2200(\Delta+50)$ & $2100(\Delta 50)$ & 50 \\
\hline III RE & 2400 & $2200(\Delta 200)$ & $2300(\Delta+100)$ & 100 \\
\hline III LE & 2400 & $2200(\Delta 200)$ & $2300(\Delta+100)$ & 100 \\
\hline IV RE & 2500 & $2200(\Delta 300)$ & $2150(\Delta 50)$ & 350 \\
\hline IV LE & 2500 & $2200(\Delta 300)$ & $2200(\Delta 0)$ & 300 \\
\hline V RE & 2500 & $2200(\Delta 300)$ & $2100(\Delta 100)$ & 400 \\
\hline V LE & 2500 & $2200(\Delta 300)$ & $2100(\Delta 100)$ & 400 \\
\hline VI RE & 2400 & $2400(\Delta 0)$ & $2300(\Delta 100)$ & 100 \\
\hline VI LE & 2400 & $2400(\Delta 0)$ & $2300(\Delta 100)$ & 100 \\
\hline VII RE & 2300 & $2200(\Delta 100)$ & $1950(\Delta 250)$ & 350 \\
\hline VII LE & 2100 & $2100(\Delta 0)$ & $2050(\Delta 50)$ & 50 \\
\hline VIII RE & 2500 & $2500(\Delta 0)$ & $2300(\Delta 200)$ & 200 \\
\hline VIII LE & 2600 & $2500(\Delta 100)$ & $2350(\Delta 150)$ & 250 \\
\hline IX RE & 2200 & $2150(\Delta 50)$ & $1500(\Delta 650)$ & 700 \\
\hline IX LE & 2200 & $2150(\Delta 50)$ & $2050(\Delta 100)$ & 150 \\
\hline $\mathrm{X} R E$ & 2700 & $2700(\Delta 0)$ & $2500(\Delta 200)$ & 200 \\
\hline X LE & 2700 & $2700(\Delta 0)$ & $2500(\Delta 200)$ & 200 \\
\hline XI RE & 2500 & $2450(\Delta 50)$ & $2200(\Delta 250)$ & 300 \\
\hline XI LE & 2350 & $2450(\Delta+100)$ & $2250(\Delta 200)$ & 100 \\
\hline XII RE & 2250 & $2150(\Delta 100)$ & $2100(\Delta 50)$ & 150 \\
\hline XII LE & 2250 & $2150(\Delta 100)$ & $2100(\Delta 50)$ & 150 \\
\hline XIII RE & 2200 & $2050(\Delta 50)$ & & \\
\hline XIII LE & 2200 & $2200(\Delta 0)$ & & \\
\hline XIV RE & 2100 & $2000(\Delta 100)$ & & \\
\hline XIV LE & 2250 & $2150(\Delta 100)$ & & \\
\hline XV RE & 2200 & $2200(\Delta 0)$ & & \\
\hline XV LE & 2200 & $2150(\Delta 50)$ & & \\
\hline XVI RE & 2100 & $2050(\Delta 50)$ & & \\
\hline XVI LE & 2100 & $1950(\Delta 150)$ & & \\
\hline XVII RE & 2400 & $2400(\Delta 0)$ & & \\
\hline XVII LE & 2400 & $2400(\Delta 0)$ & & \\
\hline
\end{tabular}

The left corneal cultures (LE) were supplemented with $25 \mu \mathrm{g} / \mathrm{ml}$ pentoxifylline, right corneal cultures (RE) were cultured under standard conditions and served as controls. video camera, and the central numerical densities estimated on video prints using the fixed frame technique.

Corneal discs, maintained in a vertical position by means of a standard holding device (Storz; no 93-100), were cultured in $60 \mathrm{ml}$ of medium (MEM supplemented with $2 \%$ fetal calf serum, glutamine, HEPES-buffer, antibiotics, and amphotericin B (all purchased from Seromed)) contained within conventional tissue culture flasks (Falcon; no 3013E): They were incubated at $37^{\circ} \mathrm{C}$ in a humidified atmosphere containing $5 \%$ carbon dioxide, with a change of medium after 10 days.

Endothelial cell numerical densities were determined before, and on days 10 and 20, of organ culturing.

\section{EXPERIMENTAL SET UP}

Corneal discs from the fellow eyes of 12 donors were evaluated in this investigation; the incidence of endothelial cell loss incurred after culturing being correlated with the presence of various cytokines released into the medium. One of each pair was incubated in the absence (right corneas), and the other (left corneas) in the presence, of pentoxifylline $(25 \mu \mathrm{g} / \mathrm{ml})$.

Samples of fluid were withdrawn for analysis between days 0 (baseline value and negative control) and 20. On day 10, the corneas were transferred to fresh medium, and culturing continued for a further 10 days under the conditions described above. Corneal discs derived from the fellow eyes of an additional five donors were cultured and analysed only between days 0 and 10 .

Aliquots of medium were screened for cytokines IL-6, IL-8, and prostaglandin E2 according to the sandwich ELISA technique. The detection level for each cytokine was 30 $\mathrm{pg} / \mathrm{ml}$.

All fluid samples, withdrawn before day 10, were tested for the presence of donor derived endotoxins using the QCL-1000 Chromogenic Limulus Amoebocyte Lysate Assay (BioWhittaker), the lower level for a positive result being set at 0.600 endotoxin units $/ \mathrm{ml}$.

\section{STATISTICAL EVALUATION}

ELISA results and endothelial cell numerical densities were compared statistically using Student's $t$ test.

The data distribution was evaluated using the Kolmogorov-Smirnov distance test.

\section{Results}

The intereye variability was normal ( $p>0.20)$.

All donor corneas lost a significant number of endothelial cells during the organ culture period ( $p<0.001$ (Fig 1)), but these losses $(2-30 \%)$ lay well within the range to be expected under such conditions (Table 1).

Samples of medium withdrawn during the initial 10 day phase of incubation registered positive for endotoxin (level $\geqslant 0.600$ units $/ \mathrm{ml}$ ) in 20 of 34 cultures (Table 2).

Supplementation of media with pentoxifylline $(25 \mu \mathrm{g} / \mathrm{ml})$ led to a significant improvement in endothelial cell survival at the end of the 20 day organ culture period $(\mathrm{p}=0.025$ 
Table 2 Donor age, postmortem time, and mean concentration of donor derived endotoxin detected within the media bathing 17 (I-XVII) fellow pairs (right eye and left eye) of cultured donor corneas during the initial 10 day phase of incubation

\begin{tabular}{|c|c|c|c|c|}
\hline \multirow{3}{*}{$\begin{array}{l}\text { Corneal pair } \\
\text { no }\end{array}$} & \multirow{3}{*}{$\begin{array}{l}\text { Donor age } \\
\text { (years) }\end{array}$} & \multirow{3}{*}{$\begin{array}{l}\text { Postmortem time } \\
\text { (hours) }\end{array}$} & \multicolumn{2}{|c|}{ Endotoxin (units/ml) } \\
\hline & & & \multicolumn{2}{|c|}{ Initial 1-10 day phase of organ culture } \\
\hline & & & $R E$ & $L E$ \\
\hline I & 24 & 21 & $0.685(+)$ & $0.715(+)$ \\
\hline II & 33 & 21 & $0.89(+)$ & $0.982(+)$ \\
\hline III & 41 & 16 & $0.429(-)$ & $0.595(-)$ \\
\hline IV & 30 & 18 & $0.720(+)$ & $0.685(+)$ \\
\hline V & 23 & 2 & $0.637(+)$ & $0.732(+)$ \\
\hline VI & 16 & 17 & $>1.0(+)$ & $>1.0(+)$ \\
\hline VII & 48 & 1 & $0.697(+)$ & $0.543(-)$ \\
\hline VIII & 45 & 21 & $0.435(-)$ & $0.482(-)$ \\
\hline IX & 56 & 2 & $0.453(-)$ & $0.548(-)$ \\
\hline $\mathrm{X}$ & 53 & 17 & $0.494(-)$ & $0.518(-)$ \\
\hline XI & 58 & 19 & $>1.0(+)$ & $>1.0(+)$ \\
\hline XII & 67 & 5 & $>1.0(+)$ & $0.298(-)$ \\
\hline XIII & 41 & 44 & $0.476(-)$ & $0.596(-)$ \\
\hline XIV & 48 & 24 & $0.857(+)$ & $0.655(+)$ \\
\hline XV & 72 & 18 & $0.554(-)$ & $0.685(+)$ \\
\hline XVI & 48 & 24 & $0.959(+)$ & $0.720(+)$ \\
\hline XVII & 40 & 26 & $0.595(-)$ & $0.631(+)$ \\
\hline
\end{tabular}

Media were considered to register negative for endotoxin (-) if the level fell below 0.600 units $/ \mathrm{ml}$ and to be endotoxin positive $(+)$ if it exceeded this value.

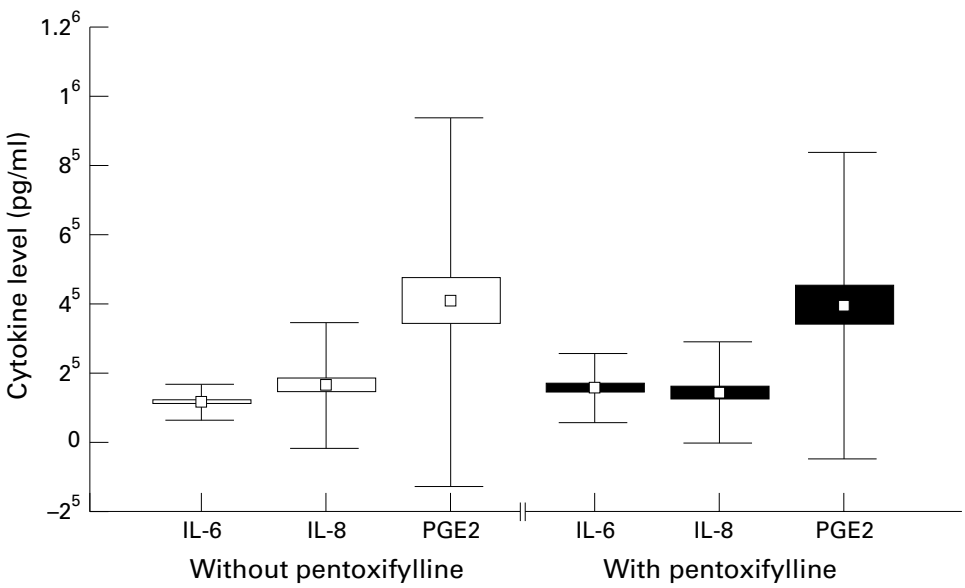

Figure 2 Levels of IL-6, IL-8, and prostaglandin E2 (PGE2) within the media of cultured corneas during the initial 10 day phase of incubation. Data pertaining to 17 fellow pairs are shown. Each box represents the mean (SD) of the final four ELISA measurements for each donor cornea. Media containing left corneas were spiked with $25 \mu \mathrm{g} / \mathrm{l}$ of pentoxifylline (solid boxes); those containing right ones served as controls (open boxes).

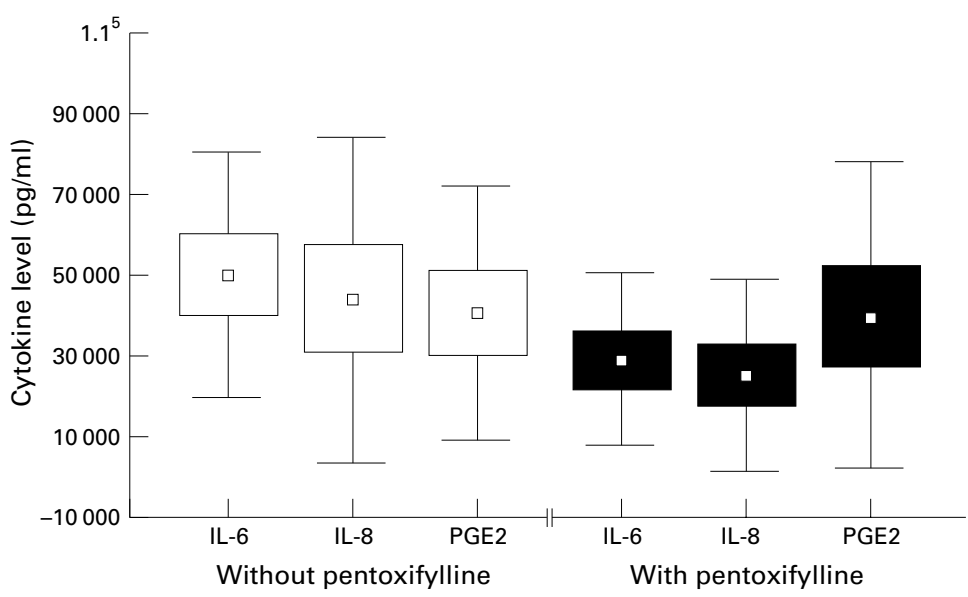

Figure 3 Levels of IL-6, IL-8, and prostaglandin E2 (PGE2) within the media of cultured corneas during the second 10 to 20 day phase of incubation. Data pertaining to 12 fellow pairs are shown. Each box represents the mean (SD) of the final four

ELISA-measurements for each donor cornea. Media containing left corneas were spiked with $25 \mu \mathrm{g} / \mathrm{l}$ of pentoxifylline (solid boxes); those containing right ones served as controls (open boxes).
(Fig 1)). The introduction of this drug was also accompanied by a significant increase in the level of IL- 6 secreted by donor corneas during the initial 10 day phase of organ culture $(\mathrm{p}$ $\leqslant 0.001$ (Fig 2)). No significant change in the level of either IL-8 or prostaglandin E2 was observed, although that of IL-8 lay below that of IL-6 in 11/17 instances.

In the absence of pentoxifylline, the level of IL-6 was significantly lower than that of IL-8 $(\mathrm{p}=0.017($ Fig 2)).

During the second phase of organ culture (days 10-20), after the change of medium, pentoxifylline $(25 \mu \mathrm{g} / \mathrm{ml})$ induced a significant decrease in the levels of both IL-6 ( $p=0.007)$ and IL-8 ( $p=0.003$ (Fig 3)), that of the latter being significantly lower than that of the former $(\mathrm{p}=0.041$ (Fig 3)).

No significant change in the level of prostaglandin E2 was invoked.

In the absence of pentoxifylline, the level of IL-6 tended to be somewhat lower than that of IL-8, also during this second phase of incubation, but the difference was not significant.

Pentoxifylline elicited no changes in the morphology of corneal endothelia.

\section{Discussion}

Inflammatory reactions, whether of extraocular or intraocular origin, tend to be downregulated by the avascular, and hence immune privileged, cornea. This feature is recognised as being essential for a favourable graft prognosis. In situ, corneal tissue is protected from potential inflammatory stimulants, such as endotoxins, by the epithelial and vascular barriers; but in vitro, the situation is different. Under these conditions, contamination of culture media with endotoxins could have untoward effects: these may be manifested either directly, by overt changes in cell morphology, and/or by a more discrete influence on the tissue's immunological status, the consequences of which may be realised only after transplantation, by a compromised graft prognosis.

In the current study, we screened the media of donor corneas cultured in the absence or presence of pentoxifylline for various cytokine mediators of the inflammatory response and compared these data with findings of endothelial cell morphology and numerical density.

The addition of pentoxifylline to culture media elicited a significant increase in the release of IL- 6 by donor corneas during the initial 10 day phase of incubation and a significant decrease during the second 10-20 day phase. In contrast, the release of IL- 8 from corneal tissue was marginally suppressed during the initial phase of incubation but decreased significantly during the second.

The relation between the levels of IL-6 and IL-8 also changed during the two phases of incubation. During the initial period no significant difference was observed between the levels of IL-6 and IL-8, but after the change of medium, the level of IL- 8 was significantly lower than that of IL-6. The relation manifested during the second phase of incubation represents an inversion of that observed under standard conditions in the absence of pentoxifylline. 
Pentoxifylline also elicited a significant improvement in endothelial cell survival at the end of the culturing period.

As previous studies have revealed, the levels of IL-6 and IL-8 under standard conditions and after endotoxin stimulation are highest during the initial 10 day phase of incubation, ${ }^{35}$ when the autocrine or paracrine functions of responsive cells intrinsic to the cornea or belonging to the passenger pool (for example, macrophages, Langerhans cells, or lymphocytes) are still operative. But during the change of medium, at least a portion of the responsive cells may be readily dislodged and washed away. Alternatively, the susceptible cell population may dislodged and washed away or become refractory. ${ }^{35}$

IL-6 is expressed by a number of cell types, and has an important role in host defence and immune responses. It regulates $\mathrm{T}$ lymphocyte function, and enhances the expression of $\mathrm{Fc}$ receptors on macrophages as well as stimulates their phagocytic activity. In endotoxin induced uveitis, IL-6 has been shown to elicit more damage than endotoxin itself when injected intravitreally, and is known to increase the expression of HLA class II antigens, a finding which may be of particular relevance in corneal grafting. ${ }^{39}$

The secretion of IL- 8 by organ cultured corneas may play a part in directing the migration of leucocytes towards this tissue from neighbouring ones. Infiltration of the cornea with such cells is a characteristic of both infectious and non-infectious ocular inflammation, including keratitis, uveitis, and allograft rejection. ${ }^{40}$ And the production of IL- 8 by corneal tissue in culture may thus have important clinical consequences.

Since up to $50 \%$ of organ culture media may contain endotoxins, in spite of their being sterile, ${ }^{36}$ instances of endothelial cell death may be partially attributable to these substances being carried over with excised tissue and their subsequent stimulation of cytokine production. These latter mediators of inflammation may, in turn, elicit an increased expression of HLA class II antigens, which, by upregulating the recipient's local immune response, may lead to graft rejection and failure.

This study has demonstrated that when organ culture media are supplemented with pentoxifylline, these deleterious effects may be eschewed, as evidenced by the improved survival of endothelial cells. Hence, the routine addition of this drug to organ culture media could have a beneficial influence not only on the condition of the donor corneas but also on their clinical course after grafting. It should be borne in mind, however, that the half life of pentoxifylline in organ culture media has not yet been determined and that the techniques currently implemented for measuring donor derived endotoxin cannot distinguish between small quantities of this substance with high activity and large quantities with low activity. The clinical course of pentoxifylline supplemented organ cultured donor corneas also needs to be evaluated before we can draw any definitive conclusions.
The authors would like to express their appreciation to Dr C England for her assistance in preparation of the manuscript and to Ms F Flückiger and Ms M Gygax for their technical assistance.

1 Balazs C, Kiss E. Immunological aspects of the effect of pentoxifylline (Trental). Acta Microbiol Immunol Hun pentoxifylline

2 Dong RP, Umezawa Y, Ikushima $H$, et al. Differential regulatory effects of pentoxifylline on human $\mathrm{T}$ cell activation pathways. F Clin Immunol 1997; 17:247-52

3 D'Hellencourt CL, Diaw L, Cornillet P, et al. Differential regulation of TNF alpha, IL-1 beta, IL-6, IL-8, TNF beta, and IL-10 by pentoxifylline. Int $\mathcal{F}$ Immunopharmacol 1996; 18:739-48.

4 Bienvenu J, Doche C, Gutowski MC, et al. Production of proinflammatory cytokines and cytokines involved in the TH1/TH2 balance is modulated by pentoxifylline. $f$ Cardiovasc Pharmacol 1995;25(Suppl 2):80-4.

5 Van Furth AM, Verhard-Seijmonsbergen EM, van Furth R, et al. Effect of lisofylline and pentoxifylline on bacterialstimulated production of TNF-alpha, IL-1 beta, IL-10 by human leukocytes. Immunology 1997;91:193-6.

6 Windmeier C, Gressner AM. Pharmacological aspects of pentoxifylline with emphasis on its inhibitory actions on hepatic fibrogenesis. Gen Pharmacol 1997;29:181-96.

7 Chaouat G, Assal Meliani A, Martal J, et al. IL-10 prevents naturally occuring fetal loss in the $\mathrm{CBA} \times \mathrm{DBA} / 2$ mating combination, and local defect in IL-10 production in this abortion-prone combination is corrected by in vivo injection of IFN-tau. F Immunol 1995;154:4261-8.

8 Van Leenen D, van der Poll T, Levi M, et al. Pentoxifylline attenuates neutrophil activation in experimental endotoxattenuates neutrophil activation in experimental end

9 Zabel P, Schoenharting MM, Schade FU, et al. Effects of pentoxifylline in endotoxinemia in human volunteers. Progr Clin Biol Res 1991;367:207-13.

10 Koo DJ, Yoo P, Cioffi WG, et al. Mechanism of the beneficial effects of pentoxifylline during sepsis: maintenance of adrenomedullin responsiveness and downregulation of proinflammatory cytokines. I Surg Res 2000;91:70-6.

11 Krysztopik RJ, Matheson PJ, Spain DA, et al. Lazaroid and pentoxifylline suppress sepsis-induced increases in renal vascular resistance via altered arachidonic acid metabolism. F Surg Res 2000;93:75-81.

12 Nelson JL, Alexander JW, Mao JX, et al. Effect of pentoxifylline on survival and intestinal cytokine messenger RNA transcription in a rat model of ongoing peritoneal sepsis. Crit Care Med 1999;27:13-19.

13 Zabel P, Schade FU, Schlaak M. Inhibition of endogenous TNF formation by pentoxifylline. Immunobiology 1993;187: 447-63.

14 Reimund JM, Dumont S, Muller CD, et al. In vitro effects of oxpentoxifylline on inflammatory cytokine release in patients with inflammatory bowel disease. Gut 1997;40: 475-80.

15 Diaz-Granados N, Howe K, Lu J, et al. Dextran sulfate sodium-induced colonic histopathology, but not altered epithelial ion transport, is reduced by inhibition of phosphodiesterase. Am f Pathol 2000;156:2169-77.

16 Navarro J, Punzon MC, Pizarro A, et al. Pentoxifylline inhibits acute HIV-1 replication in human T cells by a mechanism not involving inhibition of tumor necosis factor synthesis or nuclear factor-kappa B activation. AIDS 1996; 10: 469-75.

17 Bergese SD, Pelletier RP, Vallera D, et al. Regulation of endothelial VCAM-1 expression in murine cardiac grafts. Roles for TNF and IL-4. Am f Pathol 1995;146:989-98.

18 Bergese SD, Huang EH, Pelletier RP, et al. Regulation of endothelial VCAM-1 expression in murine cardiac grafts. Expression of allograft endothelial VCAM-1 can be manipulated with antagonist of INF-alpha or IL- 4 and is not required for allograft rejection. Am F Pathol 1995;147: 166-75.

19 Swartbol P, Truedson L, Paersson $\mathrm{H}$, et al. Tumor necrosis factor-alpha and interleukin- 6 release from white blood cells induced by different graft materials in vitro are affected by pentoxifylline and iloprost. $\mathcal{F}$ Biomed Mater Res 1997;36:400-6.

20 Clark SC, Sudarshan C, Roughan J, et al. Modulation of reperfusion injury after single lung transplantation by penreperfusion injury after single lung transplantation by pen-
toxifylline, inositol polianions, and sin-1. $\mathcal{F}$ Thorac Cardiovasc Surg 1999;117:556-64.

21 Noel C, Copin MC, Hazzan M, et al. Immunomodulatory effect of pentoxifylline during human allograft rejection: involvement of tumor necrosis factor-alpha and adhesion molecules. Transplantation 2000;27:1102-7.

22 Van Furth AM, Steenwijk TM, Langermans JA, et al. In vitro effect of dexamethasone, pentoxifylline, and antiendotoxin monoclonal antibody on the release of proinflammatory mediators by human leukocytes stimulated with Haemophilus influenzae type B. Pediatr Res 1994;35: 725-8.

23 Park WS, Chang YS, Lee M. The efficacy of pentoxifylline as an anti-inflammatory agent in experimental Escherichia coli meningitis in the newborn piglet. Biol Neonate 2000;77:236-42.

24 Solerte SB, Cereseni G, Ferrari E, et al. Hemorheological changes and overproduction of cytokines from immune cells in mild to moderate dementia of the Alzheimer's type: cells in mild to moderate dementia of the Alzheimer's type: Aging 2000;21:271-81. 
25 Van Furth AM, Verhard-Seijmonsbergen EM, Langermans JA, et al. Effect of xanthine derivatives and dexamethasone on Streptococcus pneumoniae-stimulated production of tumor necrosis factor alpha, interleukin-1 beta (IL-1 beta) and IL- 10 by human leukocytes. Clin Diagnc Lab Immuno 1995;2:689-92

26 Hoskin DW, Phu T, Makrigiannis AP. Pentoxifylline inhibits granzyme $\mathrm{B}$ and perforin expression following T-lymphocyte activation by anti-CD 3 antibody. Int $\mathcal{F}$ Immunopharmacol 1996;18:623-31.

27 Bengtsson A, Redl H, Schlag G, et al. Effects on complement activation and cytokine (TNF-alpha and IL-8) release on infusion of anti-TNF-antibodies or a xanthine derivative (HWA 138) in septic baboons. Acta Anaesthesiol Scand 1996;40:244-9.

28 Krakauer T. Pentoxifylline inhibits ICAM-1 expression and chemokine production by proinflammatory cytokines in human pulmonary epithelial cells. Immunopharmacology 2000;46:253-61.

29 Rieneck K, Diamant M, Haahr PM, et al. In vitro immunomodulatory effects of pentoxifylline. Immunol Let 1993;37:131-8

30 Fang CC, Yen CJ, Chen YM, et al. Pentoxifylline inhibits human peritoneal mesothelial cell growth and collagen synthesis: effects on TGF-beta. Kidney Int 2000;57:262633.

31 Hasebe Y, Thomson LR, Dorey CK. Pentoxifylline inhibition of vasculogenesis in the neonatal rat retina. Invest Ophthalmol Vis Sci 2000;41:2774-8.

32 Mandell GL. Cytokines, phagocytes and pentoxifylline. $\mathcal{F}$ Cardiovasc Pharmacol 1995;25(Suppl 2): 20-2.
33 Accardo-Palumbo A, Triolo G, Carbone MC, et al. Polymorphonuclear leukocyte myeloperoxidase levels in patients with Behçet's disease. Clin Exp Rheumatol 2000;18: $495-8$

34 Biemond BJ, Levi M, Ten Cate $\mathrm{H}$, et al. Plasminogen activator and plasminogen activator inhibitor I release during experimental endotoxaemia in chimpanzees: effect of interventions in the cytokine and coagulation cascades. Clin Sci 1995; 88:587-94.

35 Sobottka Ventura AC, Engelmann K, Dahinden C, et al. Endotoxins modificate the autocrine function of organcultured donor corneae and increase the incidence of endothelial cell loss. Br f Ophthalmol 1997;81:1093-8.

36 Sobottka Ventura AC, Pels E, Engelmann K, et al. Detection of endotoxin in media from sterile organ cultures. Ger $\mathcal{F}$ Ophthalmol 1997;5:404-7.

37 Sobottka Ventura AC, Böhnke M. Toxicity of pentoxifylline on monolayers of highly proliferating cells of epithelial origin. F Ocul Pharmacol Ther 1999;15:525-35.

38 Boehnke M. Donor tissue for keratoplasty. Report experiences by the Hamburg cornea bank. Klin Monatsbl Augenheilkd 1991; 198:562-71.

39 Hoekzema R, Verhagen K, Van Haren MAC, et al. Endotoxin-induced uveitis in the rat: significance of intraocular interleukin 6. Invest Ophthalmol Vis Sci intraocular int

40 Elner VM, Strieter RM, Pavilak MA, et al. Human corneal interleukin-8. IL-1 and TNF-induced gene expression and secretion. Am f Pathol 1991;139:977-88. 